\section{CONSTRUCTIONAL MODIFICATION OF AN EXTRUSION DIE}

LUDOVIT KOLLATH ${ }^{1}$, ANDREJ VENGER ${ }^{1}$, ERNEST GONDAR ${ }^{2}$, MIROSLAV BOSANSKY ${ }^{3}$

${ }^{1}$ Institute of Manufacturing Systems, Environmental Technology and Quality Management, Faculty of Mechanical Engineering, STU in Bratislava, Slovakia 2 Institute of technologies and materials, Faculty of Mechanical Engineering, STU in Bratislava, Slovakia ${ }^{3}$ Institute of transport technology and designing, Faculty of Mechanical Engineering, STU in Bratislava, Slovakia

DOI : 10.17973/MMSJ.2019_03_201813

e-mail: ludovit.kollath@stuba.sk

The paper deals with design and optimization of an extrusion die which consists of a die body and a set of replaceable plugs for various extrusion cross-sections. This system is primarily used for producing WPC products on the laboratory extruder EUROTECH EB30. The paper offers several designs of extrusion dies and examines their advantages as well as disadvantages. Based on this analysis, the best design is chosen and then flow simulations through a die and by FEA are done.

Keywords

Wood, plastics, composite, WPC, extruder, die, extrusion, FEA, flow simulation

\section{INTRODUCTION}

One of the most widely used method for the WPC manufacturing is extrusion. Extrusion is continuous pushing of material through the tool - die. Die determines shape of final product during extrusion. For complex profiles it is very difficult to design die and design quality still depends to a large extent on the constructor's empirical data. At present there is software allowing simulation of material flow through die and therefore die designing and optimizing is faster and easier.

Our new die designs have been formed with a certain relationship to the original die, because of some structural dimensions which had to be respected.

The task was based on the previous experiences with the production of WPC on a laboratory extrusion line EUROTECH EB30. There have been several unsuccessful attempts to extrude the wood-plastic composite through the old die. All the attempts ended by extrusion of the burnt materials or by clogging the die. As the primary cause of failure we have identified the bad design of the extrusion head + the die. This whole part (the extrusion head + the die) has universal character. From the screw extruder the material does not flow directly into the die, but into the eccentric head. By rotating the eccentric, it is possible to adjust the flow of the material either to the pelletizing head or to the die for continuous extrusion.
Moreover this path to the die is leading through another "turn" (so that the material is extruded parallel to the screw axis). In this area there is an excess resistance against the material flow and therefore in our opinion this design solution is an inappropriate one.

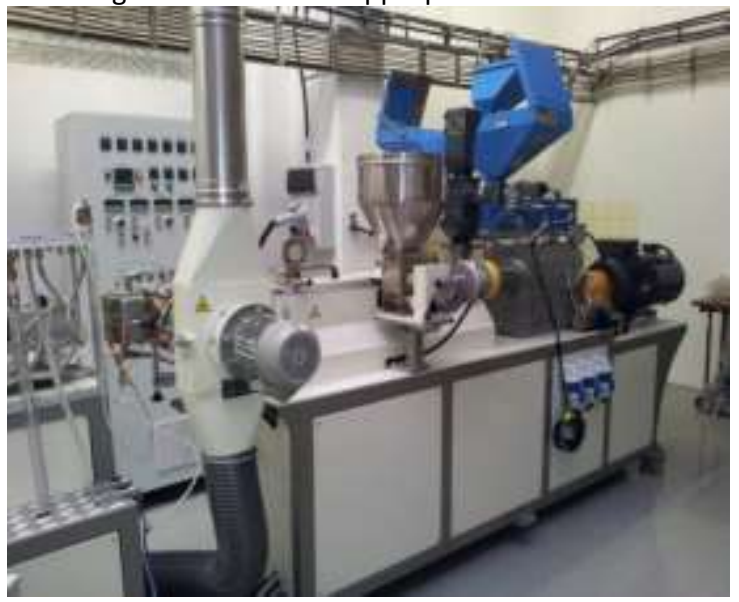

Figure1. Extruder EUROTECH EB30

\section{ORIGINAL SOLUTION}

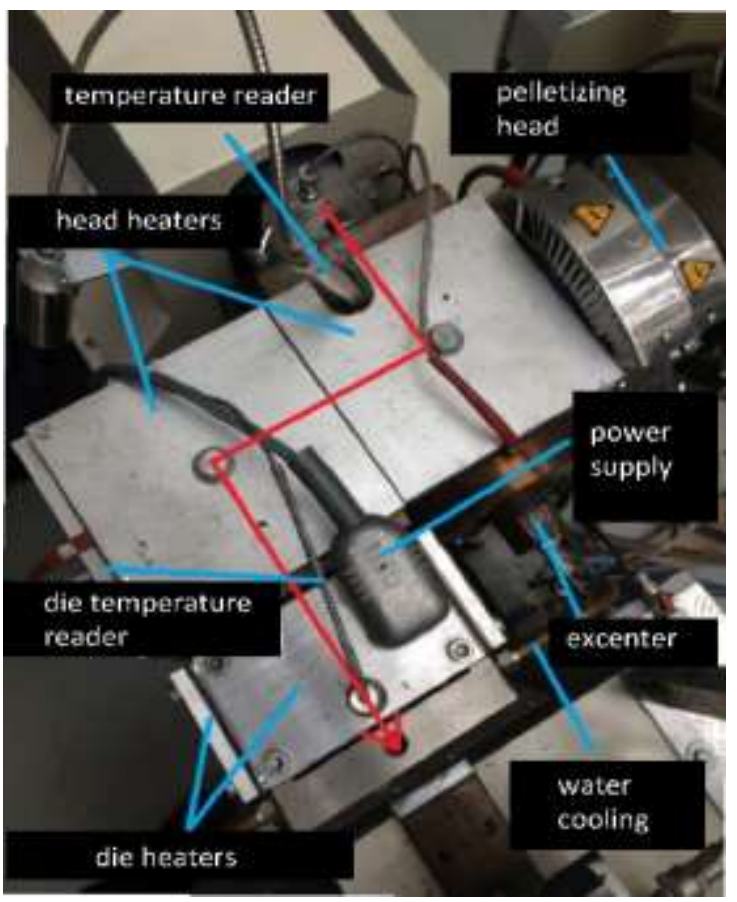

Figure 2. Original extrusion head and die

The top view of the die is shown in Figure 2. The red arrow shows material flow from the extruder into the die. As already mentioned, by placing the die right behind the extruder it is possible to avoid two turns that would significantly facilitate material flow. The picture shows also the power supplied heaters with the temperature readers. After heating to work temperature it is possible to rotate the excenter to change current flow.

All four pieces (parts) of the old die are made of the same material. The material chemical analysis has shown the die material is the most similar to ferritic steel alloyed with molybdenum $\mathrm{X} 6 \mathrm{CrMoNb} 17-1$. Its precise 
chemical composition is given by the chemical analysis report.

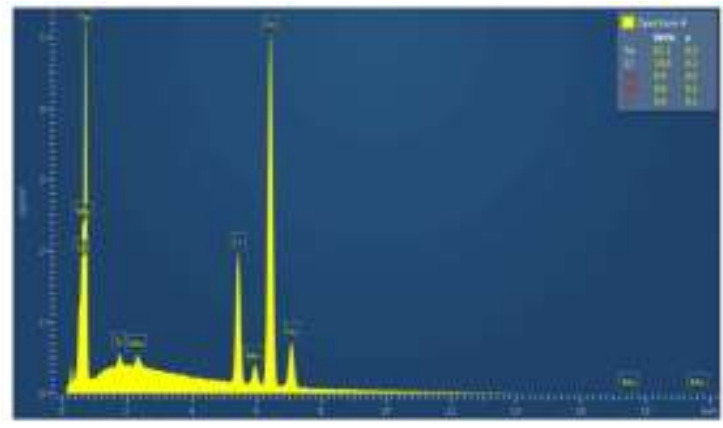

Figure 3. Chemical composition of the original die

The material shows an exceptional resistance to corrosion, machinability, chemical resistance, polishability and exceptional mechanical properties. Based on these properties the material has been found suitable for a new die design.

\section{STARTING POINTS FOR NEW SOLUTION}

All general recommendations (according to professional literature) on character and die construction can be summarized in the following points [Rauwendaal 2014], [Michaeli 2003], [Kostic 2011]:

- No "stagnation areas" in flow passage - areas where material flow is being slowed down or stopped;

- $\quad$ Fluent flow rate increase along flow passage; Simple installing and disassembling;

Length of relaxing area should be 10 times larger than diameter of flow passage- but not too long as this increases pressure gradient and decreases extrusion rate;

- If possible prevent sudden changes in flow passage shape - if possible use small converging angles, within range: $10-30^{\circ}$;

- Use large radii (either outer or inner) instead of sharp edges - the smallest radius possible: $3 \mathrm{~mm}$;

- Keep the same wall thickness - for uniform temperature regulation;

- $\quad$ Prevent too thick walls;

- Construct inner walls thinner than outer walls - because of cooling;

- Minimize using hollow areas - it is very difficult to reach high precision;

- Die should consist of several parts (with the same width for temperature regulation if possible);

- Flow passage axis should be symmetrical to outer walls - due to heat conduction;

- Minimize quantity of elements in flow passage;

- Secure minimum pressure gradient in die through simulations;

- The better roughness the better conditions for material flow, however maximum roughness is Ra 6.3;

- Secure the most uniform material flow possible.

All the above-mentioned recommendations and limitations have been included into a new die design
The old die consists of four parts. Regarding the existing heating and cooling system of the original extrusion head and die, this design of four parts has been observed in the new head and die. The main aim has been to exclude two $90^{\circ}$ flow direction turns and to solve a requirement for die "versatility" regarding shapes of extruded profiles. To search for a solution and decide on dimensions and angles we have simulated (by Flow Simulation 2017 Solid Works Program) material flow in the old die and in several alternative solutions for the new die.

We have chosen a concept of assembled head and die, it means the joint connection consists of four parts as the original one, but the inlet channel can be changed by replaceable plug (Figure 4).

The objective of the simulation has been to search for right sizes of two parameters (radius and angle) of inlet flow passage and their mutual position with regard to the subsequent marginal conditions:

- $\quad$ Flow passage inlet diameter must be $d=25 \mathrm{~mm}$;

- $\quad$ Flow passage outlet diameter must be $d=5 \mathrm{~mm}$;

- Minimum relaxation length in this case is 50mm;

- $\quad$ Reduction angle of flow passage diameter must be $30^{\circ}$ maximum.

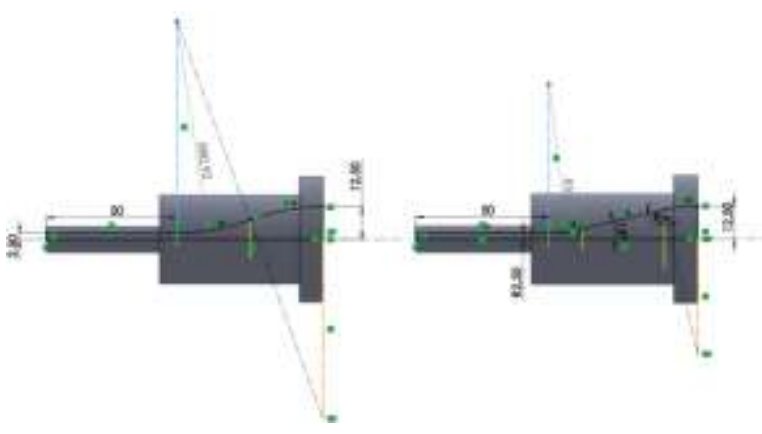

Figure 4. Inlet flow passage scheme

In total, 12 alternative solutions have been simulated based on the considered dimensions according to Table 2.

\begin{tabular}{|c|c|c|c|c|c|}
\hline $\begin{array}{c}\text { radius }[\mathrm{mm}] \\
\left.\text { angle }^{\circ}\right]\end{array}$ & 40 & 70 & 100 & 130 & 140 \\
\hline 12 & YES & YES & NO & NO & NO \\
\hline 13 & YES & YES & YES & NO & NO \\
\hline 14 & YES & YES & YES & NO & NO \\
\hline 15 & YES & YES & YES & YES & NO \\
\hline
\end{tabular}

Table 1. Angle and radius design

Set simulation parameters must be same for all designs. The set parameters were:

- Heat conduction in solids: $\square$;

- Time-dependent simulation: $\square$; Influence of gravity (Y-axis direction): $\square$, Solids material: stainless steel 302, Wall temperature: $450 \mathrm{~K}$, Wall roughness: $1.6 \mu \mathrm{m}$, Outlet flow volume: 27475 . 10-5 m3 . s-1,

- Atmospheric pressure and outlet temperature: $101325 \mathrm{~Pa}$ and 300K,

- Mesh: automatic,

- $\quad$ Flowing medium: PE. 
Unfortunately, at this stage of research not all relevant WPC parameters are available to simulate under real WPC parameters. However, we assume that PE flow simulation results show suitability of our die construction modifications (Figure 6).
Table 2 shows that, in every respect, the best combination is $\varphi=15^{\circ}, r=130 \mathrm{~mm}$. The second-best combination is $\varphi=13^{\circ}, r=100 \mathrm{~mm}$.

\begin{tabular}{|c|c|c|c|c|c|c|}
\hline Goal (Value) & $\begin{array}{l}\varphi=12^{\circ}, \\
r=40 \mathrm{~mm}\end{array}$ & $\begin{array}{l}\sin ., 2 x \\
r=81 \mathrm{~mm}\end{array}$ & $\begin{array}{l}\varphi=12^{\circ}, \\
r=70 \mathrm{~mm}\end{array}$ & $\begin{array}{l}\varphi=13^{\circ}, \\
r=40 \mathrm{~mm}\end{array}$ & $\begin{array}{l}\varphi=13^{\circ}, \\
r=70 \mathrm{~mm}\end{array}$ & $\begin{array}{l}\varphi=13^{\circ}, \\
r=100 \mathrm{~mm}\end{array}$ \\
\hline static pressure $[\mathrm{Pa}]$ & 33950632,03 & $\begin{array}{l}36732 \\
236,35\end{array}$ & $\begin{array}{l}34071 \\
291,75\end{array}$ & $\begin{array}{l}36624 \\
269,56\end{array}$ & $\begin{array}{l}35342 \\
082,25\end{array}$ & 33684122,41 \\
\hline $\begin{array}{l}\text { absolute pressure } \\
{[\mathrm{Pa}]}\end{array}$ & 33950645,12 & $\begin{array}{l}36732 \\
250,06\end{array}$ & $\begin{array}{l}34071 \\
304,60\end{array}$ & $\begin{array}{l}36624 \\
283,34\end{array}$ & $\begin{array}{l}35342 \\
095,48\end{array}$ & 33684135,05 \\
\hline dynamic pressure $[\mathrm{Pa}]$ & 13,09 & 13,71 & 12,85 & 13,78 & 13,24 & 12,63 \\
\hline speed $[\mathrm{m} / \mathrm{s}]$ & 0,0698 & 0,0688 & 0,0685 & 0,0692 & 0,0686 & 0,0681 \\
\hline force $[N]$ & 16799,69 & 18172,68 & 16858,08 & 18119,78 & 17485,52 & 16666,94 \\
\hline forceX) $[N]$ & $-0,05$ & $-0,39$ & $-0,22$ & $-0,34$ & $-0,33$ & 0,84 \\
\hline force $(\mathrm{Y})[\mathrm{N}]$ & $-2,79$ & $-2,16$ & $-2,21$ & $-1,85$ & $-1,87$ & $-2,00$ \\
\hline force $(\mathrm{Z})[\mathrm{N}]$ & $-16799,69$ & $-18172,68$ & $-16858,08$ & $-18119,78$ & $-17485,52$ & $-16666,94$ \\
\hline shear force $[\mathrm{N}]$ & 869,09 & 944,07 & 894,57 & 947,53 & 916,98 & 881,89 \\
\hline shear force $(X)[N]$ & 123,20 & 131,56 & 131,59 & 132,18 & 131,55 & 131,44 \\
\hline shear force $(\mathrm{Y})[\mathrm{N}]$ & 0,66 & 0,30 & 0,36 & 0,34 & 0,29 & 0,29 \\
\hline shear force $(\mathrm{Z})[\mathrm{N}]$ & $-860,31$ & $-934,86$ & $-884,84$ & $-938,26$ & $-907,49$ & $-872,04$ \\
\hline shear stress [Pa] & 35229,65 & 38020,22 & 36003,23 & 38301,78 & 36914,70 & 35402,72 \\
\hline shear stress $(\mathrm{X})[\mathrm{Pa}]$ & 4469,55 & 4748,95 & 4722,97 & 4789,80 & 4734,06 & 4697,68 \\
\hline shear stress $(\mathrm{Y})[\mathrm{Pa}]$ & 24,03 & 10,79 & 12,90 & 12,48 & 10,37 & 10,48 \\
\hline shear stress $(\mathrm{Z})[\mathrm{Pa}]$ & $-31211,38$ & $-33745,38$ & $-31757,95$ & $-34000,98$ & $-32658,09$ & $-31166,57$ \\
\hline $\begin{array}{l}\text { input static pressure } \\
{[\mathrm{Pa}]}\end{array}$ & 34330311,28 & $\begin{array}{l}37134 \\
846,43\end{array}$ & $\begin{array}{l}34456 \\
558,73\end{array}$ & $\begin{array}{l}37026 \\
721,34\end{array}$ & $\begin{array}{l}35734 \\
739,67\end{array}$ & 34065466,00 \\
\hline $\begin{array}{l}\text { output static pressure } \\
{[\mathrm{Pa}]}\end{array}$ & 100490,98 & 100490,98 & 100490,99 & 100490,98 & 100490,99 & 100490,99 \\
\hline pressure gradient $[\mathrm{Pa}]$ & 34229820,30 & $\begin{array}{l}37034 \\
355,46\end{array}$ & $\begin{array}{l}34356 \\
067,74\end{array}$ & $\begin{array}{l}36926 \\
230,36\end{array}$ & $\begin{array}{l}35634 \\
248,68\end{array}$ & 33964975,01 \\
\hline
\end{tabular}

Table 2 Results of different combinations of angle with radii

\section{CONCLUSIONS}

The most important parameter of all is pressure, which course is shown on Figure 5, more precisely pressure gradient and force, more precisely its component in Z-axis. The lower pressure gradient arises in flow passage, the higher performance can be reached. Z-axis force component will be used again for inspecting screw connections in strength analysis. The graph shows that $15^{\circ}$ angle offers the widest range of achievable pressures and it is possible to achieve the highest number of combinations.

Based on the analysis and evaluation of the simulation results new drawings of head and die with replaceable plug have been drawn up.
Dependency of static pressure course on reduction angle and radius size

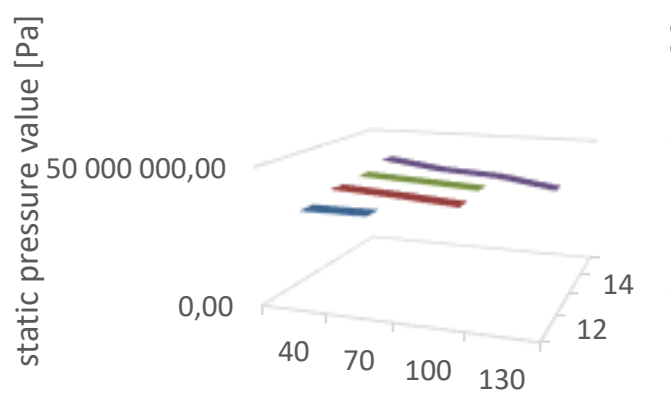

radius size $[\mathrm{mm}]$

a $12 \square 13 \square 14 \quad 15$ 


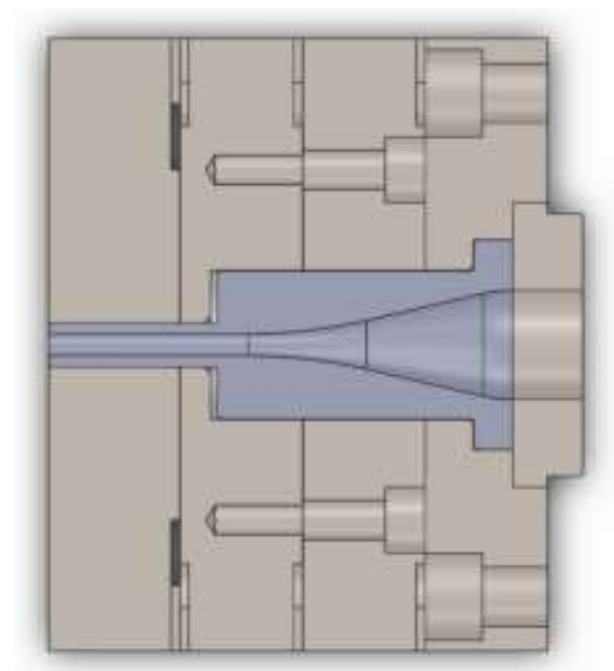

Figure 6. Plug placing

\section{ACKNOWLEDGMENTS}

This work was based on the results of the research project VEGA 1/0394/16 titled "Studying the possibility of preparing and applying composite materials from waste wood and plastic."

\section{REFERENCES}

[Rauwendaal 2014] Rauwendaal, C. Polymer Extrusion. 5. vyd. Munich: Hanser Publishers, 2014. 950 s. ISBN 978-156990-516-6.

[Michaeli 2003] Michaeli, W. Extrusion Dies. Munich: HANSER, 2003. 362 s. ISBN 3-446-22561-7.

[Kostic 2011] Kostic, M. M., Reifschneider, L. Design of Extrusion Dies. [cit: 10-5-2017]. http://file.seekpart.com/keywordpdf/2011/1/12/201111243 62064.pdf

\section{CONTACTS}

Prof Miroslav Bošanský

STU in Bratislava

Faculty of Mechanical Engineering

Institute of transport technology and designing

Nam. slobody 17, 81231 Bratislava, Slovak Republic e-mail: miroslav.bosansky@stuba.sk

www.stuba.sk

Prof. Ernest Gondar

STU in Bratislava

Faculty of Mechanical Engineering

Department of Technology and Materials,

Pionierska 15, 83102 Bratislava, Slovak Republic

e-mail: ernest.gondar@stuba.sk

www.stuba.sk

Assoc. Prof. Ludovit Kollath

STU in Bratislava

Faculty of Mechanical Engineering

Department of manufacturing systems, environmental technology and quality management,

Nam. slobody 17, 81231 Bratislava, Slovak Republic e-mail: ludovit.kollath@stuba.sk

www.stuba.sk

MSc. (Engr.) Andrej Venger

STU in Bratislava

Faculty of Mechanical Engineering

Department of manufacturing systems, environmental technology and quality management,

Nam. slobody 17, 81231 Bratislava, Slovak Republic e-mail: andrej.venger@stuba.sk www.stuba.sk 